\title{
DINÂMICAS DO SAGRADO: FALANDO DE RELIGIÃO NO ENSINO DE SOCIOLOGIA
}

\begin{abstract}
Andrea Paiva ${ }^{1}$
RESUMO

O presente trabalho tem como objetivo realizar breves reflexões acerca da religião e do ensino de Sociologia na educação básica. Com base em questionários qualitativos e na observação participante com alunos, estagiários e professores da rede pública e privada, esta pesquisa discute a respeito de um tema aparentemente "naturalizado" ou oculto em sala de aula. A abordagem da temática religião vem ao encontro de um desafio central à imaginação sociológica. A proposta está em pensar como a religião pode contribuir para reflexões a respeito do ensino de Sociologia, quando trabalhada como atividade interlocutora dessa ação, levando em conta as observações das categorias de pensamento.
\end{abstract}

Palavras-chave: Ensino de Sociologia. Religião. Formação docente. Antropologia da Educação. Categorias de pensamento.

\section{ABSTRACT}

This study aims to conduct brief reflections on the sociology of religion and education in basic education. Based on qualitative questionnaires and participant observation with students, trainees and teachers of public and private network, this research discusses about a seemingly theme "naturalized" or hidden in the classroom. The approach of the theme religion meets a central challenge to the sociological imagination. The proposal is to think how religion can contribute to reflections on the teaching of Sociology, when worked as an interlocutor activity of this action, taking into account the comments of the categories of thought.

Keywords: Sociology of Education. Religion. Teacher training. Anthropology of Education. Categories of thought.

\section{INTRODUÇÃO}

\footnotetext{
1 Professora Adjunta Nível II do Departamento de Ciências Sociais da Universidade Federal Fluminense (UFF/Campos dos Goytacazes). Doutora em Antropologia Cultural pelo Programa de Pós-Graduação em Sociologia e Antropologia da Universidade Federal do Rio de Janeiro (PPGSAUFRJ/IFCS), onde se especializou em pesquisa sobre memória e patrimônio. Mestre pelo Programa de Pós-Graduação em Memória Social da UNIRIO. Bacharel e licenciada em Ciências Sociais pela UFRJ. É líder do Grupo de Pesquisa em Memória e Cultura Motirõ Nhãdereko. Membro do Laboratório de Pesquisa e Ensino de Ciências Sociais (LAPECS). Recentemente, vem trabalhando nas linhas de pesquisas: "Ensino de Sociologia e Sociologia da Educação" e "Memória, Religiosidade e Educação".
} 
O objetivo deste artigo é refletir sobre como o conceito de religião pode contribuir para o ensino de Sociologia na educação básica, tornando-se ponto de problematização.

Para tanto, serão utilizadas análises de questionários qualitativos e a observação participante com alunos, estagiários e professores da rede pública e privada em um município do Rio de Janeiro e em outro do Espírito Santo ${ }^{2}$.

O uso da religião, seja como conceito, seja como tema, está relacionado a um desafio central que vem dinamizando a didática do ensino de Sociologia: a necessidade de despertar no aluno a imaginação sociológica. A proposta está em pensar como a religião pode contribuir para reflexões a respeito do ensino de Sociologia, quando trabalhada como atividade interlocutora dessa disciplina.

O trabalho visa, também, iniciando com os conceitos de religião, estabelecer breves relações entre a Antropologia da Educação e o ensino de Sociologia, ao partir de considerações iniciais que percorrem essas temáticas, como o exercício do estranhamento e a desnaturalização, que descrevem aspectos favoráveis à articulação entre essas duas disciplinas.

A escolha pela pesquisa foi estimulada quando lecionava Sociologia no Ensino Médio, em instituições privadas e públicas. Foi através de experiências na sala de aula que comecei a perceber a dificuldade em abordar a Sociologia e a questão religiosa que por vezes invadia as discussões, mesmo quando se retratavam alguns autores clássicos da Sociologia - seja na apresentação de algumas biografias de vida, seja na formulação de alguns de seus conceitos, seja nos estudos sobre cultura. Esta pesquisa não surgiu com o intuito de reprodução de um discurso de oposição entre ciência e religião, mas de compreender como esses conceitos são trabalhados em sala de aula pelos professores de Sociologia.

A inclusão da Sociologia como disciplina obrigatória nos três anos do Ensino Médio, estabelecida pela Lei n. 11.684/2008, aumentou as expectativas pela

2 Este trabalho é resultante de parte da pesquisa que venho desenvolvendo na UFF/Campos, intitulada "Entre o sagrado e o profano: o ensino de sociologia como campo de observação". A identificação dos atores envolvidos será fictícia como forma de preservar as identidades dos informantes. Inicialmente, a inclusão do estado do Espírito Santo à pesquisa se deve à formação docente de profissionais de Sociologia que desenvolvemos em Campos e também à nossa atuação nesse estado. 
DINAMICAS DO SAGRADO: FALANDO DE RELIGIÃO NO ENSINO DE SOCIOLOGIA Andrea Paiva

construção de novos padrões de interlocução entre o campo científico e o campo escolar. Essa discussão já vinha sendo produzida na busca pela identidade da disciplina ${ }^{3}$ e pela criação da Associação Brasileira de Ensino de Ciências Sociais (ABECS), em 2012.

Sendo assim, o desafio deste trabalho está em pensar como a abordagem sobre religião em sala de aula nos permite visar um debate complexo a respeito não apenas dessa questão, mas também do próprio ensino de Sociologia, buscando soluções mais adequadas para o exercício da atividade docente.

\section{"QUAL É A SUA RELIGIÃO, PROFESSORA?"}

Em 2010, ao explicar sobre os modos de produção, iniciei a discussão apresentando o sociólogo alemão Karl Marx, quando uma aluna exclamou: "Ih! Lá vem o ateu!"4. No decorrer de minhas experiências docentes, ouvi e fui colecionando frases, em minhas memórias e no meu diário de aula, do tipo: "Qual a sua religião, professora?", "Todo mundo que leciona Sociologia é ateu, né, professora?", "O nosso professor antigo de Sociologia dizia que todo sociólogo é ateu, porque não pode ter religião", dentre outras observações. Sempre fui curiosa em compreender as premissas que percorriam essas questões: como se reproduziam essas ideias? $\mathrm{O}$ que pensavam a respeito? Por que há oposição entre ciência e religião em uma disciplina que tem como pressuposto básico o estudo das relações sociais? O que os autores envolvidos (docentes e discentes) teriam a dizer sobre?

3 Seja na busca pelo histórico da disciplina, realizada em manuais e material didáticos, seja na análise e elaboração de currículo em meio às experiências e pesquisas docentes, conforme podemos perceber em trabalhos anteriores à Lei 11.684/2008, como os de Meucci (2000), Sarandy (2004), Moraes (2003), Santos (2002), nas produções de artigos e eventos sobre o tema, como vem sendo desenvolvido pelo Laboratório de Ensino de Sociologia Florestan Fernandes (LABES), pela Faculdade de Educação da UFRJ, pelo Laboratório de Pesquisa e Ensino de Ciências Sociais (LAPECS), na UFF/Campos, e por diferentes olhares da contribuição da Antropologia, mais fortemente com Dauster (2007), Gusmão (1997), Oliveira (2012) e Roch e Tosta (2008), acerca do ensino de Sociologia.

4 Não se trata de uma norma, mas dos autores que vêm sendo classificados como "clássicos da Sociologia", dentre eles Karl Marx, Emille Durkheim e Max Weber, observando que o primeiro tornase mais familiar entre os alunos nas disciplinas de História e Geografia, em geral, nas discussões acerca do sistema econômico capitalista e na abordagem histórica sobre trabalho e os diferentes modos de produção.

Inter-Legere - Revista de Pós Graduação em Ciências Sociais da UFRN Natal RN, ISSN 1982-1662 no 18, jan./jun. de 2016 p. 95-115 
Nessa reflexão, em que saber ouvir carrega, junto ao olhar, um significado específico ao cientista social (CARDOSO DE OLIVEIRA, 1996), venho observando que a religião nas narrativas de alunos e professores em sala de aula pode ser compreendida como uma linguagem por meio da qual cada um dos indivíduos codifica suas mensagens através de símbolos e interpretações muito particulares a suas crenças e a sua moral ${ }^{5}$.

Um dos questionamentos mais comuns que ouvi das minhas turmas, independentemente de ser em escola pública ou privada, especulava acerca de minha crença, embora nunca tenha comparecido com símbolos religiosos, afirmado pertencer ou simpatizar com alguma religião ou determinado tipo de crença e narrado a respeito das minhas pesquisas em mestrado e doutorado sobre a questão religiosa. "Qual a sua religião, professora?" e as afirmativas: "A senhora tem cara de espírita”; "Não, ela é boazinha. Tem Jesus e Maria no coração. É católica!", "É evangélica, porque não fala palavrão", "É muito calma, acredita em Deus!", “Você é muito calma. Não tem cara de bater tambor porque lá tem muita confusão, muito conflito. Cruz credo!", “É católica, né, professora? Porque é humana” eram frases presentes em minhas aulas de Sociologia no Ensino Médio. Diante desse contexto, parafraseando Lévi-Strauss (2004), fui amadurecendo e investigando que os estudos sobre religiões e crenças se caracterizam como "bons para pensar" o ensino de Sociologia.

Contudo, dentre tantas frases, há uma que parece atuar como uma espécie de "mito de origem" em todas as escolas onde lecionei e que sempre me trouxe o desejo de especular mais sobre o assunto: "Qual é a sua religião, professora?". Essa pergunta me trazia desafios didáticos ao ensino de Sociologia no que dizia respeito à prática de atuação docente, à suposta "neutralidade" entre docente e discente, bem como ao pesquisador e seu objeto de estudos. Não era apenas a minha identidade como professora e pesquisadora que se encontrava como autoinvestigação, mas também os desafios teóricos e práticos em lidar com os

5 Cito o conceito de moral, no sentido aplicado por Durkheim (2011), como um fato social exterior ao indivíduo e que tem como função a regulação social. 
DINAMICAS DO SAGRADO: FALANDO DE RELIGIÃO NO ENSINO DE SOCIOLOGIA Andrea Paiva

conceitos e temas de ciência e religião e a forma como os alunos os observam em sua realidade social.

Em muitos momentos das aulas de Sociologia que ministrei no Ensino Médio e dos estágios que venho supervisionando, percebo que os alunos assimilam a teoria com base em seus valores morais e religiosos, parecendo ordenar a busca pela compreensão do mundo social.

Florestan Fernandes (1975), em uma das suas reflexões apontadas sobre os sentidos da Sociologia para "alterar o sistema brasileiro", interrogava: é a Sociologia capaz de tornar a educação um "instrumento consciente de progresso social nos diferentes meios sociais em que se integra o Brasil?":

O ensino das Ciências Sociais no curso secundário seria uma condição natural para a formação de atitudes capazes de orientar o comportamento humano no sentido de aumentar a eficiência e a harmonia de atividades baseadas em uma compreensão racional das relações entre os meios e os fins, em qualquer setor da vida social (FERNANDES, 1975, p. 106).

Nesse contexto, faz-se necessário compreendermos que o conhecimento sociológico é um saber científico mais profundo, não menos qualificado do que um conhecimento do senso comum, porém diferenciado em suas bases de construção teórica e empírica pelo saber, pois ele envolve a tomada de consciência da ação humana de forma responsável e comprometida e da realidade social observada, conduzindo-nos para uma relação de dádiva entre indivíduos e sociedades.

Pensar a Sociologia como ciência da sociedade traz como um desafio docente, constantemente, a reflexão inicial entre aquilo que é classificado pelos alunos como conhecimento do senso comum (dotado de experiência nas crenças e critérios pessoais de verdade) e senso científico (pautado nas experiências metodológicas capazes de direcionar a investigação e a análise).

Normalmente, os alunos narram suas interpretações sobre a disciplina sem a clara distinção das formas de conhecimentos, por mais que a etapa inicial das aulas de Sociologia consista em apresentar bases do conhecimento do senso comum e científico, em apontar a Sociologia como uma ciência social e o exercício constante da imaginação sociológica. 
Em questionário aplicado aos professores de Sociologia, alguns deles apontaram ser o tema da religião problemático em um lócus onde a maioria dos alunos segue um determinado tipo de religião, em especial, a neopentecostal e a católica $^{6}$. Para muitos, embora fossem necessários a abordagem religiosa e o próprio ensino religioso - desde que contextualizasse a história das religiões e não incentivo e prática de uma determinada crença -, falar sobre religião os colocava diante de algo "muito particular" e, desse modo, tendencioso ao conflito. Muitos diziam evitar tocar no assunto, visto que não dispunham ainda de "método e diálogo" para abordá-lo.

Em uma breve experiência em sala de aula, ao tratar da cultura e colocando em prática reflexões sobre os conceitos de relativismo cultural e etnocentrismo, exemplifiquei com base na polêmica reportagem em 06 de junho de 2011 sobre as jogadoras do futebol do Irã, que usaram uniforme islâmico, acarretando uma provável proibição das atletas às Olimpíadas de 2012 devido à veste ${ }^{7}$. Enquanto explicava, um aluno me interrompeu, dizendo: "Queria ser sociólogo, mas descobri agora que eu não posso". Perguntei por que e a reposta veio logo: "A senhora com certeza é 'ateu', porque mostra muita coisa sem se envolver. Eu sou cristão e não concordo com essa cultura (se referindo à cultura islâmica) e nem com a do índio. Para fazer Sociologia não pode falar nem ter religião". Logo, um outro aluno manifestou: "Todo professor de Sociologia é ateu, todos professores de Sociologia que eu tive falavam isso: ciência é ciência, religião é religião". Porém, nessas constantes frases, onde entra a Sociologia enquanto ciência (que tem como propósito discutir diversos aspectos da vida social, dentre eles o religioso)?

6 Em dados demográficos do IBGE, no ano de 2010, o município de Campos dos Goytacazes tinha uma população de 463.731 pessoas, apresentando um total de 3.227 sujeitos de 10 anos ou mais de idade com rendimentos de $1 / 8$ salários-mínimos e religião católica apostólica romana, bem como 3.157 que se declaravam evangélicos. Disponível em: <http://www.cidades.ibge.gov.br/rio-dejaneiro|campos-dos-goytacazes|censo-demografico-2010:-resultados-da-amostra-religiao> Acesso em: 07 dez. 2015. Nesses dados, é possível observar o contraste presente nos estudos sobre religião quando os indivíduos tendem a responder perguntas sobre a sua religiosidade.

7 Disponível em: <http://esporte.ig.com.br/futebol/uniforme+islamico+causa+polemica+no+futebol+feminino/n15970046 69592.html>. Acesso em: 12 jun. 2011. 
DINAMICAS DO SAGRADO: FALANDO DE RELIGIÃO NO ENSINO DE SOCIOLOGIA Andrea Paiva

Começamos, então, por uma breve discussão acerca de ciência, religião e sociedade.

Em uma breve abordagem sobre a Sociologia das religiões a partir de alguns clássicos, Durkheim (1996) já afirmava a não existência de religiões falsas ao analisar a diversidade cultural e apontar para a função da religião: fortalecer os laços da coesão social e contribuir para a solidariedade dos membros do grupo, destacando-se cerimônias e rituais que ganham grande importância por possibilitarem o encontro dos fiéis e a reafirmação de suas crenças. A crença em divindades e na vida após a morte contribui para a definição da religiosidade e se explica na experiência do sagrado, que tem como função operar no encantamento do mundo ao proporcionar ritos (DOUGLAS, 1976). Entretanto, essas ações ainda são constantes desafios ao homem ocidental moderno, como aponta Eliade (1992, p. 13):

O homem ocidental moderno experimenta um certo mal-estar diante de inúmeras formas de manifestações do sagrado: é difícil para ele aceitar que, para certos seres humanos, o sagrado possa manifestarse em pedras ou árvores, por exemplo.

A respeito da crença na "ciência", Mills (1969, p. 23) já trazia questionamentos acerca do seu papel, demonstrando a ambiguidade do conceito ao afirmar:

Muito do que se considerava como "ciência" passou a ser visto hoje como uma filosofia dúbia; muito do que se considerava como "verdadeira ciência" frequentemente nos proporciona apenas fragmentos confusos das realidades entre as quais vive o homem. Homens de ciência, pelo que se acredita geralmente, já não tentam retratar a realidade como um todo ou apresentar um esboço verdadeiro do destino humano. Além disso, a "ciência" parece muito menos um elemento moral criador e uma forma de orientação do que um grupo de Máquinas Científicas, operadas por técnicos e controladas por economistas e militares, que não a representam nem a compreendem como ética e orientação. Enquanto isso, os filósofos que falam em nome da ciência com frequência a transformam num "cientificismo", considerando sua experiência idêntica à experiência humana e pretendendo que somente pelos seus métodos podem os problemas da vida ser resolvidos. Com tudo isso, muitos trabalhadores culturais passaram a considerar a "ciência" como um 
DINAMICAS DO SAGRADO: FALANDO DE RELIGIÃO NO ENSINO DE SOCIOLOGIA Andrea Paiva

falso e pretensioso Messias, ou pelo menos um elemento altamente ambíguo na civilização moderna.

Essas ações nos colocam diante de um paradoxo na formação docente, a respeito da relação entre ciência e religião. Como analisado por Willaime (2012, p. 13),

o nascimento da sociologia como ciência não pode ser dissociado dos questionamentos ligados ao futuro do religioso nas sociedades ocidentais. Seria impossível para os primeiros sociólogos, ao tentarem entender a emergência da sociedade moderna, não se deparar com o fenômeno religioso. A sociologia das religiões nasceu, efetivamente, no âmago das questões sociológicas sobre modernidade e todos os grandes fundadores da disciplina (a começar por Durkheim e Weber) propuseram uma análise sociológica dos fenômenos religiosos.

\section{"MULHER, FUTEBOL E RELIGIÃO NÃO SE DISCUTEM, NÉ, PROFESSORA?": OS DESAFIOS DA IMAGINAÇÃO SOCIOLÓGICA NO ENSINO DE SOCIOLOGIA}

Quando Wright Mills (1969, p. 11-12) escreveu acerca da imaginação sociológica, no capítulo intitulado "A Promessa", já direcionava pontos básicos sobre sua análise do conceito:

A imaginação sociológica capacita seu possuidor a compreender o cenário histórico mais amplo, em termos de seu significado para vida íntima e para carreira exterior de numerosos indivíduos. Permite-lhe levar em conta como os indivíduos, na agitação de sua experiência diária, adquirem frequentemente uma consciência falsa de suas posições sociais. Dentro dessa agitação, busca-se a estrutura da sociedade moderna, e dentro dessa estrutura são formuladas as psicologias de diferentes homens e mulheres. Através disso, a ansiedade pessoal dos indivíduos é focalizada sobre fatos explícitos e a indiferença do público se transforma em participação nas questões públicas. O primeiro fruto dessa imaginação - e a primeira lição da ciência social que a incorpora - é a ideia de que o indivíduo só pode compreender sua própria experiência e avaliar seu próprio destino localizando-se dentro de seu período; só pode conhecer suas possibilidades na vida tomando-se cônscio das possibilidades de todas as pessoas, nas mesmas circunstâncias em que ele. Sob muitos aspectos, é uma lição terrível; sob muitos outros, magnífica. [...] A imaginação sociológica nos permite compreender a história e a

Inter-Legere - Revista de Pós Graduação em Ciências Sociais da UFRN

Natal RN, ISSN 1982-1662 no 18, jan./jun. de 2016 p. 95-115 
DINAMICAS DO SAGRADO: FALANDO DE RELIGIÃO NO ENSINO DE SOCIOLOGIA Andrea Paiva

biografia e as relações entre ambas, dentro da sociedade. Essa é a sua tarefa e sua promessa.

Dentre as tantas definições sobre a imaginação sociológica ao longo de suas análises, há uma que vem ao encontro da proposta das questões discutidas neste artigo:

A capacidade de passar de uma perspectiva a outra - da política para a psicológica; do exame de uma única família para a análise comparativa dos orçamentos nacionais do mundo; da escola teológica para a estrutura militar; de considerações de uma indústria petrolífera para estudos da poesia contemporânea. É a capacidade de ir das mais impessoais e remotas transformações para as características mais íntimas do ser humano - e ver as relações entre as duas. Sua utilização se fundamenta sempre na necessidade de conhecer o sentido social e histórico do indivíduo na sociedade e no período no qual sua qualidade e seu ser se manifestam (MILLS, 1969, p. 13-14).

Sendo assim, o que podemos extrair dessas definições é que a imaginação sociológica é de grande importância para o exercício didático e reflexivo do ensino de Sociologia na educação básica, se nos concentrarmos na compreensão da história e da biografia dos indivíduos na sociedade onde vivem. Ou seja, como contribuição ao ensino de Sociologia, a recusa dessa atividade de nada adiantaria se não houvesse a comunicação docente com a realidade de vida dos discentes para tal exercício da imaginação sociológica. Trazer a religião como tema a ser discutido não deve ser visto como sinônimo de "ensino religioso", nem como "orientação religiosa", mas como desafios em se propor sua abordagem.

A investigação de um tema apoiado na sociologia da experiência de François Dubet (1994), centrada nas ações dos atores sociais, permite a criação de canais diretos de diálogos também entre a universidade e a escola, ao reunir docentes e discentes, do ensino superior e médio, em seminários, grupos de estudos e cursos de extensão, somando-se ao exercício da imaginação sociológica. Dubet (1994) direciona para os estudos das representações e condutas dos atores e, particularmente, para as formas como eles explicam suas ações. 


\section{INTER-LEGERE}

DINAMICAS DO SAGRADO: FALANDO DE RELIGIÃO NO ENSINO DE SOCIOLOGIA Andrea Paiva

Podemos, assim, analisar que a intervenção sociológica deve ser mais uma etapa necessária à sociologia da experiência, na medida em que se concretiza em diálogo com os atores investigados.

A docência precisa ser compreendida enquanto prática social e o ambiente educacional enquanto espaço sociocultural no qual as práticas de culturas são realizadas e manifestadas. O professor, enquanto intelectual dessa experimentação, tem como ofício o exercício da indissociabilidade entre teoria e prática. A reflexão deve ser constituída e formada na prática, fazendo com que o aluno seja capaz de exercer uma espécie de hermenêutica da experimentação, ao expressar e trabalhar com os temas que observa "afetar" e "incomodar" a sua realidade social. Para tanto, é importante investigar o perfil dos estudantes, coletando dados acerca das motivações que conduzem suas reflexões sobre o tema e o conceito da religião, como também a respeito de outros, classificados como "transversais", como a sexualidade.

Os processos culturais e sociais que levam à escolha de um tema, conceito e teoria não devem escapar, em grande parte, às nossas ações concretas propositais de natureza e política ideológica. Dessa maneira, torna-se importante pensar nas categorias de pensamento como forma de expressar e aguçar a imaginação sociológica.

Um dos conceitos que podem auxiliar a imaginação sociológica está na observação atenta do professor às categorias de pensamento produzidas pelos discursos na escola pelos alunos e docentes da disciplina. Segundo Durkheim (1996), as categorias são necessárias porque são indispensáveis ao funcionamento do pensamento. Elas tornam-se eficazes para entendermos os sistemas classificatórios de um determinado estudo. Sua origem está na vida social, na medida em que os homens são socializados e participam de uma determinada coletividade. Para pensar tantas interrogações, é necessário um olhar cuidadoso sobre as categorias de pensamento.

No caso relatado acima, podemos listar algumas das classificações trazidas pelos discentes, tais como: católica $=$ boa, ciência $X$ religião; ser humano $=$ ter religião $X$ não ter religião $=$ palavrão $=$ conflitos, que nos colocam em contato com 
DINAMICAS DO SAGRADO: FALANDO DE RELIGIÃO NO ENSINO DE SOCIOLOGIA Andrea Paiva

sistemas classificatórios capazes de expressar categorias e pensamentos. Os homens não classificam naturalmente sua realidade social, como apontam Durkheim e Mauss (2001). Eles se utilizam de sistemas classificatórios para expressarem a origem das suas ideias e onde podemos encontrá-las. A capacidade de definir, deduzir, expressar-se em linguagem e induzir são características essenciais da humanidade e que variam na história.

A religião pode contribuir para reflexões acerca do ensino de Sociologia quando trabalhada como atividade interlocutora dessa ação. Exercícios a esse respeito podem ser feitos com base nas categorias de pensamentos. $O$ questionamento da religião e da ciência como categorias de pensamento pode se tornar um elo importante para a presente articulação, contribuindo para pensar a prática docente. Nesse sentido, o estudo das categorias de pensamento, contribuição da tradição antropológica, é marcado pela descoberta e análise de categorias aparentemente estranhas ao pensamento ocidental. Interrogar-nos a respeito da dualidade ciência e religião é buscar perguntas e respostas sobre o que elas nos dizem quanto às sociedades que as produziram e as produzem, como também compreender que quando os homens pensam e classificam estão se referindo a algo a respeito de como eles são e como pensam a realidade social.

Sendo assim, podemos considerar as categorias de pensamento como contribuições importantes do que vem sendo classificado como "Antropologia da Educação", "Antropologia e Educação"8 ao ensino de Sociologia.

Diante de perguntas feitas pelos alunos a respeito da religião, percebe-se a necessidade de pensar quais questões e problemáticas envolvem essa relação entre docente e discente no ensino de Sociologia e até que ponto a religião se apresenta "oculta" ou "naturalizada" pelos docentes e discentes, como estigma social ou

8 Vem crescendo a quantidade de Grupos de Trabalho (GTs) e mesas-redondas em congressos de antropologia, como a Associação Brasileira de Antropologia (ABA) e a Reunião Internacional de Antropologia do Mercosul (RAM), e de autores que versam a respeito da contribuição da Antropologia, embora a nomenclatura "Antropologia da educação", "Antropologia e Educação" e "Antropologia na educação" ainda seja uma problemática inicial à discussão. Para esses autores (GUSMÃO, 1997; DAUSTER, 2007; ROCHA; TOSTA, 2008; OLIVEIRA, 2012), as contribuições que o olhar antropológico pode oferecer tanto nas pesquisas quanto na prática educacional problematizam a relação entre ambas, apontando as fronteiras entre os saberes que envolvem a Antropologia e, consequentemente, as contribuições e desafios ao ensino de Sociologia.

Inter-Legere - Revista de Pós Graduação em Ciências Sociais da UFRN Natal RN, ISSN 1982-1662 no 18, jan./jun. de 2016 p. 95-115 
DINAMICAS DO SAGRADO: FALANDO DE RELIGIÃO NO ENSINO DE SOCIOLOGIA Andrea Paiva

baseada em condições que nos remetem à posição do que é visto como "sagrado e "profano", plausível à investigação.

Aplicamos um questionário com um professor de Sociologia, o qual classificarei como professor X, 32 anos, que se denominou como "Crente em Jesus Cristo, embora eu seja membro de Igreja Batista da Convenção Batista Brasileira"”.

O professor ensina na rede pública no município de Campos dos Goytacazes. Em resposta sobre como observava a questão religiosa por seus professores do ensino superior, afirmou que eles se mostravam "distantes de picuinhas 'sobrenaturais'". Informou, inclusive, que um professor que era pastor jamais teria feito qualquer menção religiosa: "Como aluno é curioso, acabamos descobrindo. Era um excelente prof. de Ciência Política, trabalha com mídia e religião. Mais especificamente: coronelismo eletrônico evangélico". Ao se tornar professor de sociologia do Ensino Médio, afirmou não falar sobre religião em sala de aula: "Não. Entretanto, dependendo da intervenção do aluno, é necessário um enquadramento. Enfatizo que a fé pessoal é apenas uma entre tantas".

O professor considera importante falar sobre religião quando interrogado, embora perceba a "contradição", por se tratar de um "ensino laico", mas também pelo fato de a sociologia ser uma ciência: "Embora contraditório, acho importante, mas não propício". Para ele, a maior dificuldade em abordar religião ou lidar com o assunto nas aulas de Sociologia está no fato de a Sociologia trazer como premissa a desconstrução do mundo: "Sociologia busca sempre desconstruir visões de mundo, desnaturalizar. Religião conduz as pessoas a aceitarem sem contestação".

A professora $Y$ de Sociologia, de 22 anos, vem lecionando em escolas públicas e particulares. Define-se como "religiosa" por ter sido criada na religião católica:

[...] ainda sigo, indo às missas todos os domingos, rezando algumas vezes, tendo fé em certas coisas. Embora não acredite em tudo e não concorde com várias atitudes, ideias e dogmas da Igreja. Acredito que todo ser deve ter alguma crença e fé em algo (Professora Y, questionário aplicado em 20/10/2014).

9 Questionário qualitativo aplicado em 20/11/2014.


Segundo a professora, falar sobre religião nas aulas de Sociologia é importante: "Porque eles [os alunos] têm concepções erradas sobre diversas religiões, principalmente com o candomblé e a umbanda. Por isso, acho fundamental que eles conheçam estas religiões, então eu as apresento". De acordo com ela, o momento oportuno para tratar e religiosidade na escola está nas aulas de Sociologia:

Nas aulas de Sociologia acho fundamental e nas outras áreas de humanas também é bom. Pois, para que eles entendam todo o contexto da época e do assunto de que estou tratando, às vezes saber quais eram as religiões envolvidas, é de grande relevância para compreenderem o conteúdo. E, para além disso, acho que nós professores devemos pregar na escola a tolerância religiosa, a liberdade religiosa, sempre! (Professora Y, questionário aplicado em 20/10/2014).

A professora não vê dificuldades em abordar o tema, como podemos analisar em sua reflexão:

\begin{abstract}
Não tive por enquanto nenhuma dificuldade muito grande. Mas muitos alunos que são religiosos praticantes não concordam com algumas teorias/posicionamentos sociológicos. Ainda assim, eles se dispõem a conhecê-las, se interessam, querem saber mais, me acompanham depois da aula pelos corredores para continuar o assunto. Para mim isso já é um grande avanço, esse interesse em conhecer as várias interpretações de um fato. Acredito que o meu dever seja promover e incentivar a harmonia, o respeito e não o preconceito entre todos: gays, negros, indígenas etc... Se consigo, já é muito gratificante para mim (Professora Y, questionário aplicado em 20/10/2014).
\end{abstract}

Por sua vez, a professora W, de 22 anos, demonstra uma forma de pensar diferente da professora $Y$ e do professor $X$. Leciona em diferentes redes $e$ programas de ensino no Espírito Santo, próximo à fronteira de Campos. Segundo ela: "Talvez isso se deva ao fato de que, na maioria, meus alunos são cristãos e por isso não 'preciso ter receio'”. Inicialmente, declarou falar sobre sua religião na escola: 
Sim. O pessoal sempre acha que professor de sociologia e filosofia gosta, ou tem que gostar, deste assunto. [...] Eu até afirmo que sou católica e membro atuante (ministra) da Igreja, mas reforço que meu papel ali não é catequese e que o que passo é a visão científica dos casos, assuntos. Não é algo que eu faça questão de afirmar, mas também não nego, nem me recuso. Muitas vezes, uso isso como exemplo do "estranhar o familiar", ou de respeito à diversidade (Professora W, questionário aplicado em 01/10/2014).

Para a professora W, falar de religião em sala de aula e, sobretudo, no ensino de Sociologia torna-se importante para "descortinar alguns mitos e lutar contra a intolerância religiosa. Os alunos possuem muitas visões deturpadas sobre o assunto, principalmente no que diz respeito às religiões de matriz afro".

Um ponto interessante reside na distinção que a professora faz entre religião e fé, ao afirmar que acredita ser propício falar sobre "sempre, mesmo porque esta questão muitas vezes se mostra como um dilema, 'algo que não se discute'. Por este motivo deixo claro que o que não se discute é fé, mas religião sim".

Não identificar conflitos não significa sua ausência. Ao ser interrogada sobre de que forma inicia a abordagem sobre religião, a professora $Y$ descreve:

Depende. Às vezes eu estou dando aula de um tema que não é sobre religião, mas as pessoas envolvidas têm suas religiões, a partir daí os alunos começam a perguntar: por que, quem, como? Então vamos construindo o conhecimento juntos, trocando experiências, pois tem alunos que já leram a Bíblia toda, se interessam por religião. Portanto, sabem muito do assunto. Aprendo muito com eles também. $\mathrm{E}$ eu coloco/apresento outras teorias para contrapor o que eles falam e gerar um exercício do pensamento reflexivo (Professora $Y$, questionário aplicado em 01/10/2014).

Segundo a professora $\mathrm{W}$, ao abordar religião nas aulas de sociologia é possível a identificação de um conflito acadêmico pessoal, quanto à seleção do tema:

O preconceito de alguns alunos, mas maior ainda entre a equipe escolar que não possui formação na área e que é cercada de muitos preconceitos. Este mês de setembro (para cristãos) é o mês da Bíblia. Em uma das escolas temos uma Bíblia aberta num ambiente enfeitado para isso, com uma frase bíblica. Falei com os alunos que aquilo só pode existir, se permitirem o Ramadã, Alcorão, Evangelho 
segundo Alan Kardec, dentre outros. Nesta mesma escola, todas as reuniões de formação de professores, Conselhos de Classe, são iniciados com a leitura e reflexão de um trecho da Bíblia e ao final é cedido um tempo para que professores de outras religiões possam manifestar-se. Esta manifestação nunca ocorreu. Há outras situações como orações semanais (Pai Nosso) antes da execução do Hino Nacional em uma escola e algo que começou a 15 dias mais ou menos na outra escola, sob iniciativa de professores da Renovação Carismática Católica que é a oração diária do Pai Nosso, Ave Maria, Glória e Sinal da Cruz na Sala dos professores antes de iniciarem a aula. Em nenhum dos momentos que presenciei foi comentado sobre a liberdade de outras denominações religiosas fazerem suas orações à sua maneira. Alguns professores ficam em silêncio, outros saem da sala, no momento da oração (Professora W, questionário aplicado em 01/10/2014).

A professora inicia a abordagem sobre religião, nas aulas de Sociologia, caracterizando-a "Como um aspecto da cultura do povo". No entanto, não soube citar quais atores toma como referência, mas afirmou novamente o porquê de se discutir religião nas aulas dessa disciplina:

Vou responder que: Penso que discutir religião é extremamente importante para que os alunos conheçam a diversidade e combatam preconceitos, intolerância, das quais os adeptos da umbanda, candomblé são as maiores vítimas (Professora W, questionário aplicado em 01/10/2014).

O professor Z, de 32 anos, leciona em escolas particulares católicas em Campos dos Goytacazes. Formado em Ciências Sociais, afirmou falar sobre sua religião "Quando necessário, diante de alguma pergunta digo que gosto de religar. Não importa como, onde, de que forma, em que horário, com quem [...]"10. O professor $Z$ disse que trata de religião nas aulas de Sociologia enquanto "fenômeno, manifestação, instituição, movimento e agência social". Vindo ao encontro da professora $\mathrm{Y}$, declarou ser propício discutir religião pelo viés da cultura: "Como a religiosidade faz parte da cultura, acredito que seja necessário, principalmente nas ciências humanas. O que não impede de ser propício nas outras áreas". Inicia a abordagem da religião "como fenômeno a ser pensado, refletido e entendido" e não 
DINAMICAS DO SAGRADO: FALANDO DE RELIGIÃO NO ENSINO DE SOCIOLOGIA Andrea Paiva

demonstra dificuldades em lidar com o tema nas aulas de Sociologia: "Não tenho dificuldades, pois faço um recorte da religião como fenômeno social, ou seja, como um dado que influencia a cultura, as relações, os valores (ética/moral), os esquemas de pensamentos".

É notável nas respostas dos professores uma lacuna no que diz respeito a como despertar a imaginação sociológica para a questão. A religião ainda se apresenta como um conceito muito pouco trabalhado, articulado aos temas e à teoria, como sugerem as observações das OCN de Sociologia, em que os conceitos "são elementos do discurso científico que se referem à realidade concreta" (BRASIL, 2006, p. 117). Ao trabalhar com conceitos, é necessário o seu conhecimento, inicialmente, em sua articulação com as teorias, mas também com os casos concretos à realidade social.

Partindo de uma discussão entre ciência, religiosidade e juventude e como exercício das categorias de pensamento, a antropóloga Novaes (2004) traz contribuições a essa observação ao apontar a importância de pensar "os sentidos das palavras". A análise realizada pela autora pode contribuir para a prática e a explicação sociológica em sala de aula:

O primeiro cuidado diz respeito aos sentidos das palavras "ateu", "agnóstico" e da expressão "não ter religião". Nada nos assegura que seus usos sejam os mesmos nem em termos de passado e presente, nem mesmo entre os jovens hoje entrevistados. Isto é, as autoclassificações dos jovens de hoje têm de ser pensadas em suas inter-relações no interior do campo religioso em transformação (NOVAES, 2004, p. 324).

O professor de Sociologia deve ficar atento aos "sentidos das palavras" que os alunos expressam por meio da narração, mas também àquelas que estão expostas entre os muros da escola, aparentemente "silenciadas". Essas aparecem na escola de duas formas centrais. A primeira trata da questão espacial. Em muitas escolas públicas campistas, são observadas imagens de santos, a bíblia, terços, quadros e frases religiosas. Há também pichações em que frases como "Só Jesus 
DINAMICAS DO SAGRADO: FALANDO DE RELIGIÃO NO ENSINO DE SOCIOLOGIA Andrea Paiva

salva"11, "A matéria sem Jesus não é verdadeira"12, "Não acredito em humanos. Só em Jesus!"13 percorrem os espaços das escolas. Em um segundo ponto, a religiosidade se encontra nos objetos utilizados tanto pelos docentes quanto pelos discentes: cruzes, adesivos em mochilas e cadernos, tatuagens, vestimentas e demais acessórios, como brincos, pulseiras e capas de celulares.

Outra questão na formação docente direcionada ao ensino de Sociologia é interrogar o porquê de se falar sobre o tema religião, uma vez que, quando ele é citado, está inserido em geral no tema "cultura". No entanto, vale mencionar alguns cuidados já apontados por Velho (1985, p. 14) em seus estudos acerca de desvios e divergências: "[...] desviar o foco do problema para a sociedade ou a cultura não resolve magicamente a dificuldade. É preciso verificar como a vida sociocultural é representada e percebida". Ou seja, abordar a questão religiosa enquanto sistemas simbólicos implica observar também os sistemas classificatórios, que devem sua existência às formas de organização social nas quais os homens aprendem a pensar e a utilizar conceitos.

O suporte de toda classificação é o de ser "um conjunto de hábitos mentais em virtude dos quais concebemos os seres e os fatos sob a forma de grupos coordenados e subordinados uns aos outros" (DURKHEIM; MAUSS apud MONTERO, 1986, p. 56).

Podemos, então, iniciar o debate também pela narrativa e observação corporal do aluno e do professor, ao serem abordados ou não a respeito do tema, ou quando, em aulas como as de Sociologia, Ihes é apresentado um debate sobre temas que vão de encontro a valores e morais que os indivíduos tomam para si como "verdades". É possível realizar esse exercício com base no currículo mínimo de Sociologia de 2012, nas três séries do Ensino Médio ${ }^{14}$, levando à máxima

11 Frase escrita ao lado de um quadro-negro em uma escola campista localizada no centro do município de Campos dos Goytacazes.

12 Frase pequena escrita a lápis na parte interna do muro de uma escola particular em Campos dos Goytacazes.

13 Frase escrita no banheiro feminino de uma escola pública localizada no centro do município de Campos dos Goytacazes.

14 A proposta do primeiro Currículo Mínimo foi idealizada pela SEEDUC-RJ em 2010 e colocada em prática em 2011 por uma equipe composta por um coordenador, um professor da Universidade Rural do Rio de Janeiro (UFRRJ) e seis professores da rede pública estadual que atuaram como colaboradores. No que diz respeito aos temas do terceiro ano, não abordaram apenas os temas

Inter-Legere - Revista de Pós Graduação em Ciências Sociais da UFRN Natal RN, ISSN 1982-1662 no 18, jan./jun. de 2016 p. 95-115 
observação das OCN de Sociologia, ao descreverem que "um tema não pode ser tratado sem o recurso a conceitos e a teorias sociológicas senão se banaliza, vira senso comum, conversa de botequim" (BRASIL, 2006, p. 117). Nesse sentido, é importante que haja questionamentos sobre o que se compreende por religião ao abordá-la como algo essencial nas relações sociais. Conforme aponta Simmel (2010, p. 27),

o fenômeno religioso em sua essência específica, em sua existência pura, livre de toda "coisa" empírica, é vida; o homem religioso vive de uma maneira que lhe é própria e seus processos psíquicos apresentam um ritmo, uma tonalidade, um arranjo e uma proporção de energias psíquicas que são claramente distintos daqueles que o homem teórico, artístico ou prático. Mas, tudo isso é justamente uma questão de processo e não uma formação concreta: essa vida e essa operação devem abranger os conteúdos reais e formá-los [...].

\section{CONSIDERAÇÕES FINAIS}

Observar as narrativas sobre religião que percorrem a sala de aula nos estimula a analisar como elas são expressas pelo corpo docente e discente em determinada realidade social. Nessa observação, há pontos a serem analisados e que devem ser aprofundados: como os professores de Sociologia entendem os discursos dos seus alunos? Como o tema, o conceito e a teoria vêm sendo trabalhados na escola e qual a relação do professor de Sociologia e dos alunos diante da temática? O que esperam e o que trazem?

A não abordagem da religião na escola e no ensino de Sociologia exclui não compreender a religião como uma realidade social que percorre o imaginário popular

\footnotetext{
"cultura e diversidade" e "cultura e identidade", mas também "o conhecimento sociológico" e "preconceito e identidade". No segundo ano, as temáticas foram: "Cidadania, direitos humanos e movimentos sociais", "trabalho, sociedade e capitalismo", "relações de trabalho" e "estratificação social e desigualdade". No terceiro ano: "Cultura, consumo e comunicação de massa", "poder, política e Estado", "cidadania, democracia e participação política" e "formas de violência e criminalidade". Os desafios das sugestões de como despertar a imaginação sociológica, somando-se à análise das categorias de pensamento desses temas, ainda estão sendo desenvolvidos na formação docente, em que outros temas, como sexualidade, vêm sendo colocados como pontos de reflexões. Vale destacar o trabalho de Meucci (2013) acerca do processo de formação do material didático de Sociologia (e as suas interfaces). Já dispomos de algumas considerações, no entanto, isso remete à escrita de um outro trabalho.
}

Inter-Legere - Revista de Pós Graduação em Ciências Sociais da UFRN Natal RN, ISSN 1982-1662 no 18, jan./jun. de 2016 p. 95-115 
do indivíduo em sociedade. É não buscar fazer um exercício já assumido por Mauss (MENEZES, 2003): o de aplicar o método sociológico aos fenômenos religiosos. A não abordagem do tema, assim, também impede uma discussão no ensino de Sociologia sobre ciência e religião. Não enfrentar o desafio de falar sobre religião em sala de aula é não problematizar a imaginação sociológica proposta enquanto instrumento de percepção sociológica. Nessa perspectiva, cabe ao professor de Sociologia a capacidade de análise sobre as vivências cotidianas, as relações entre elas e as situações complexas que condicionam, limitam e explicam a vida social. Desse modo, trazemos a relevância de observar as categorias de pensamento, visando, assim, contribuir para o exercício da imaginação sociológica.

Torna-se fundamental ao professor de Sociologia analisar as distâncias e aproximações das categorias não apenas no campo teórico, mas também na prática do discurso sociológico no cotidiano escolar, enquanto exercícios de estranhamento e desnaturalização dos fatos, ao apontar a igualdade perante a lei, sem distinção de qualquer natureza, sendo de caráter inviolável à liberdade de consciência e de crença.

\section{REFERÊNCIAS}

BRASIL. MEC/Secretaria de Educação Média e Tecnológica. Orientações Curriculares para o Ensino Médio. 2006. v. 3. Disponível em: $<$ http://portal.mec.gov.br/seb/arquivos/pdf/book_volume_03_internet.pdf>. Acesso em: 14 de mar. 2013.

BOURDIEU, Pierre. O poder simbólico. Rio de Janeiro: Bertrand, 2000.

CARDOSO DE OLIVEIRA, Roberto. O trabalho do antropólogo: olhar, ouvir, escrever. Revista de Antropologia, São Paulo, v. 39, n. 1, 1996.

DUBET, François. Sociologia da experiência. Lisboa: Instituto Piaget, 1994.

DAUSTER, Tania. Antropologia e educação: um saber de fronteiras. Rio de Janeiro: Forma \& Ação, 2007.

DOUGLAS, Mary. Ciência y Brujería. Barcelona: Anagrama, 1976. 
DINAMICAS DO SAGRADO: FALANDO DE RELIGIÃO NO ENSINO DE SOCIOLOGIA Andrea Paiva

DURKHEIM, Émile. Educação e Sociologia. São Paulo: Hedra, 2011.

DURKHEIM, Émile; MAUSS, Marcel. Algumas Formas Primitivas de classificação. In: MAUSS, Marcel. Ensaios de Sociologia. São Paulo: Perspectiva, 2011. p. 399-455.

DURKHEIM, Émile. As formas elementares da vida religiosa: o sistema totêmico na Austrália. São Paulo: Martins Fontes, 1996.

ELIADE, Mircea. O sagrado e o profano. São Paulo: Marins Fontes, 1992.

FERNANDES, Florestan. O ensino da Sociologia na escola secundária brasileira. In: FERNANDES, Florestan. A Sociologia no Brasil. Petrópolis: Vozes, 1975.

Originalmente publicado nos Anais do I Congresso Brasileiro de Sociologia, 21-27 de junho de 1954, em São Paulo. p. 89-106.

GUSMÃO, Neusa Maria Mendes de. Antropologia e educação: origens de um diálogo. Cad. CEDES, Campinas, 18, n. 43, dez, p. 8-25,1997.

LÉVI-STRAUSS, Claude. O cru e o cozido. São Paulo: Cosac \& Naify, 2004.

MENEZES, Renata de Castro. Marcel Mauss e a sociologia da religião. In:

TEIXEIRA, Faustino (Org.). Sociologia da religião. Petrópolis: Vozes, 2003, p. 94121.

MEUCCCI, Simone. Notas para um balanço crítico da produção recente dos livros didáticos de Sociologia no Brasil. In: OLIVEIRA, Luiz Fernandes de. Ensino de sociologia: desafios teóricos e pedagógicos para as ciências sociais. Seropédica: Ed. da UFRRJ, 2013. p. 75-82.

MEUCCI, Simone. A institucionalização da sociologia no Brasil: os primeiros manuais e cursos. 2000. Dissertação (Mestrado em Sociologia) - Universidade Estadual de Campinas, Campinas, 2000.

MILLS, C. Wright. A imaginação sociológica. Rio de Janeiro: Zahar, 1969.

MONTERO, Paula. Magia e pensamento mágico. São Paulo: Ática, 1986.

MORAES, Amaury César. Licenciatura em Ciências Sociais e Sociologia. Tempo Social, São Paulo, v. 15, n. 1, p. 5-20, maio 2003.

NOVAES, Regina. Os jovens "sem religião": ventos secularizantes, "espírito de época" e novos sincretismos. Notas preliminares. Estudos Avançados, São Paulo, v. 18, n. 52, p. 321-330, 2004. 
OLIVEIRA, Amurabi. Antropologia e Antropólogos, Educação e Educadores: O lugar do ensino de Antropologia na formação docente. PerCursos, Florianópolis, v. 13, p. 120-132, 2012.

ROCHA, Gilmar; TOSTA, Sandra. Antropologia e Educação. Belo Horizonte: Autêntica, 2008.

SILVA, Ileizi. Das fronteiras entre ciência e educação escolar: As configurações do ensino das ciências sociais/sociologia no estado do Paraná (1970-2002). 2006. Tese (Doutorado em Sociologia) - Universidade de São Paulo, São Paulo, 2006.

SANTOS, Mário. A sociologia no ensino médio: o que pensam os professores da rede pública do Distrito Federal. 2002. Dissertação (Mestrado em Sociologia) Universidade de Brasília, Brasília, 2002.

SARANDY, Flávio Marcos. A sociologia volta à escola: um estudo dos manuais de sociologia para o ensino médio no Brasil. 2004. Dissertação (Mestrado em Sociologia) - Universidade Federal do Rio de Janeiro, Rio de Janeiro, 2004.

SEEDUC-RJ. Currículo Mínimo de Sociologia - 2012. Rio de Janeiro: SEEDUCRJ, 2012. Disponível em: <http://www.rj.gov.br/web/seeduc/exibeconteudo?articleid=374742 $>$. Acesso em: 12 ago. 2012.

SIMMEL, Georg. Religião: ensaios. São Paulo: Olho d'Água, 2010. v. 1.

VELHO, Otávio. Desvio e divergência: uma crítica da patologia social. Rio de Janeiro: Zahar, 1985.

WILLAIME, Jean-Paul. Sociologia das religiões. São Paulo: Unesp, 2012. 